Check for updates

Cite this: RSC Adv., 2019, 9, 28851

Received 25th June 2019

Accepted 2nd September 2019

DOI: $10.1039 / c 9 r a 04771 a$

rsc.li/rsc-advances

\title{
Research on the thermal conductivity and dielectric properties of AIN and BN co-filled addition-cure liquid silicone rubber composites
}

\begin{abstract}
Zhenzhen Ou, Feng Gao, Huaijun Zhao, Shumeng Dang and Lingjian Zhu (D)*
The present work aims at studying the thermal and dielectric properties of addition-cure liquid silicone rubber (ALSR) matrix composites using boron nitride (BN) and aluminum nitride (AIN) as a hybrid thermal conductive filler. Composite samples with different filler contents were fabricated, and the density, thermal conductivity, thermal stability, dielectric properties, and volume resistivity of the samples were measured. According to the experimental results, the density, thermal conductivity, dielectric constant and dielectric loss tangent values all increased with the increasing addition of filler. When the weight fraction of hBN filler was $50 \mathrm{wt} \%$, the thermal conductivity of composites was $0.554 \mathrm{~W}\left(\mathrm{~m}^{-1} \mathrm{~K}^{-1}\right)$, which is 3.4 times higher than that of pure ALSR. The corresponding relative permittivity and dielectric loss were 3.98 and 0.0085 at $1 \mathrm{MHz}$, respectively. Furthermore, TGA results revealed that the AIN/BN hybrid filler could also improve the thermal stability of ALSR. The volume resistivity of ALSR composites was higher than that of pure ALSR. The addition of fillers improved the thermal properties of ALSR and had little effect on its insulation properties. This characteristic makes ALSR composites attractive in the field of insulating materials.
\end{abstract}

\section{Introduction}

With the development of microelectronic integration technology and application under high frequency and high power conditions, electrical equipment is constantly becoming smaller, which causes the heat production per unit area of electronic equipment to increase rapidly.$^{1-3}$ According to BarCohen $e t$ al., the stability of electronic devices will decrease by $10 \%$ with every $2{ }^{\circ} \mathrm{C}$ increase in temperature. ${ }^{4}$ Therefore, effective dissipation of accumulated heat is important to ensure the stability and lifetime of the electronic equipment. The research on the thermal conductivity of electronic packaging materials is becoming more and more important. With the advantages of excellent electrical insulation, chemical resistance, weather resistance, hydrophobicity, low shrinkage and no by-product release during cross-linking, addition-cure liquid silicone rubber (ALSR) is thought to be a good packaging material in high-voltage electrical equipment, although it has low thermal conductivity (about $0.125-0.25 \mathrm{~W}\left(\mathrm{~m}^{-1} \mathrm{~K}^{-1}\right)$ ). ${ }^{5,6}$ At present, the thermal conductivity of polymers for electronic packaging is reinforced by filling with high thermal conductivity but electrically insulating particles,${ }^{7,8}$ such as aluminum nitride (AlN), ${ }^{9}$ boron nitride (BN), ${ }^{10,11}$ silicon carbide (SiC), ${ }^{12}$ and alumina $\left(\mathrm{Al}_{2} \mathrm{O}_{3}\right) \cdot{ }^{13}$ There have been many studies on the influences of particle size and geometry, surface treatment and

Xi'an University of Technology, Xi'an 710048, Shaanxi, China. E-mail: zlj_zhy@xaut. edu.cn; Tel: $+86-029-82312861$ orientation of fillers on the thermal conductivity of polymerbased composites. ${ }^{14-17}$ For example, Liu et al. studied the effects of BN nanoplates as filler on the thermal diffusivity/ conductivity, electrical breakdown strength, mechanical performance, dielectric behaviour, and hydrophobicity properties of high temperature vulcanized silicone rubber. ${ }^{18}$ It was reported that after adding BN nanoplates the thermal conductivity could be increased by $30 \%$, the electrical breakdown strength and hydrophobicity were also improved. Aluminum nitride was added as thermal conductive filler at weight fractions of $16.67 \mathrm{wt} \%, 21.05 \mathrm{wt} \%$, and $28.57 \mathrm{wt} \%$ to pristine silicone rubber in ref. 19. Thermal conductivity of all three aluminum nitride/silicone rubber composites were increased $27.9 \%, 41.4 \%$, and $43.7 \%$ than that of the pristine silicone rubber. It has already been explored that the better performance can be achieved by using two or more traditional fillers. Kim et al. reported that the synergistic effect of spherical $\mathrm{Al}_{2} \mathrm{O}_{3}$ and $\mathrm{BN}$ nanoplatelets for efficient thermal transport in polymer composites. ${ }^{20}$ Addition of $\mathrm{BN}$ nanoplatelets boosted thermal conductivity of $\mathrm{Al}_{2} \mathrm{O}_{3}$-containing polymer composites up to $3.6 \mathrm{~W}\left(\mathrm{~m}^{-1} \mathrm{~K}^{-1}\right)$ which was more than double the thermal conductivity of pristine polymer composites without BN nanoplatelets. Zha et al. focused on the effect of micro-Si ${ }_{3} \mathrm{~N}_{4}$ and nano- $\mathrm{Al}_{2} \mathrm{O}_{3}$ mixture on thermal conductivity, dielectric and mechanical properties of the SR composites. With the addition of micro-Si $\mathrm{N}_{4}$-nano- $\mathrm{Al}_{2} \mathrm{O}_{3}$ mixture at $30 \mathrm{vol} \%\left(\mathrm{Si}_{3} \mathrm{~N}_{4} / \mathrm{Al}_{2} \mathrm{O}_{3}=\right.$ 26/4), the composites showed high thermal conductivity of $1.6 \mathrm{~W}\left(\mathrm{~m}^{-1} \mathrm{~K}^{-1}\right)$, low relative dielectric permittivity of 5.3 and 
high breakdown strength of $85 \mathrm{MV} \mathrm{m}{ }^{-1} \cdot{ }^{21}$ However, the research on ALSR is mainly focused on its tracking resistance, flame retardancy ${ }^{22-24}$ and thermal degradation mechanism. ${ }^{25}$

There are few studies on filling ceramic particles to improve the thermal conductivity of ALSR. In this work, commercially available boron nitride and aluminum nitride was investigated as the hybrid thermal filler to prepare ALSR composites. The synergistic effect of boron nitride and aluminum nitride on the thermal conductivity, thermal stability, breakdown strength, dielectric properties, and volume resistivity before and after thermal aging of the ALSR composites were investigated.

\section{Materials and methods}

\subsection{Materials}

Vinyl-terminated poly-dimethylsiloxane (Vi-PDMS, viscosity 1000 cSt and vinyl content $0.96 \mathrm{wt} \%$ ), poly-hydromethylsiloxane (PHMS, viscosity 20-30 cSt and hydride content $0.3 \mathrm{wt} \%$ ) were purchased from Zhejiang Xin'an Chemical Industry Group Co., Ltd., China. Platinum(0)-1,3-divinyl-1,1,3,3-tetramethyldisiloxane complex solution (Karstedt's catalyst, platinum content 3000 ppm), 1-ethynyl-1-cyclohexanol (inhibitor), and 3-aminopropyl triethoxysilane (KH550) were purchased from Shanghai Aladdin Biochemical Technology Co., Ltd., China.

Hexagonal boron nitride (h-BN; thermal conductivity, $33 \mathrm{~W}$ $\left(\mathrm{m}^{-1} \mathrm{~K}^{-1}\right)$; relative dielectric permittivity, 4.0; average sizes, 0.5 $\mu \mathrm{m}$; density, $2.25 \mathrm{~g} \mathrm{~cm}^{-3}$; purity, 99.9\%) and aluminium nitride (thermal conductivity, $240 \mathrm{~W}\left(\mathrm{~m}^{-1} \mathrm{~K}^{-1}\right)$; relative dielectric permittivity, 4.0; average sizes, $10 \mu \mathrm{m}$; density, $3.26 \mathrm{~g} \mathrm{~cm}^{-3}$ ) were purchased from Ke Gong Metallurgy Material Co., China.

Absolute ethanol (purity, 99.7\%) was obtained from Sinopharm Chemical Reagent Co., Ltd. (Shanghai, China). Distilled water was self-prepared in the laboratory.

\subsection{Surface modification}

Silane coupling agent KH550 was used to pre-treat the surfaces of the ALN and BN particles to ensure better dispersion and reduce thermal resistance of filler and matrix. At first, $0.75 \mathrm{~g}$ of $\mathrm{KH}-550$ was mixed in $20 \mathrm{~g}$ of absolute ethanol, and mechanical stirrer was used to stir mixed solution to achieve sufficient hydrolysis of the coupling agent. Then, $50 \mathrm{~g}$ of ALN particles or $\mathrm{BN}$ particles were dispersed in $300 \mathrm{~g}$ of absolute ethanol by sonication for $60 \mathrm{~min}$. After that, the hydrolysed coupling agent added dropwise to the mixed solution of filler and ethanol. The obtained mixture was put into a water bath at $80{ }^{\circ} \mathrm{C}$ and stirred with mechanical stirrer for 4 hours. Finally, the mixture was filtered and dried in a vacuum oven at $110{ }^{\circ} \mathrm{C}$ for 12 hours.

\subsection{Sample preparation}

Vi-PDMS, PHMS, ALN, BN, 1-ethynyl-1-cyclohexanol and Karstedt's catalyst were sequentially mixed, using a mechanical stirrer with $700 \mathrm{rpm}$ in rotation speed for $120 \mathrm{~min}$. Among them, the molar ratio of Vi-PDMS to PHMS satisfied $n_{\mathrm{Si}-\mathrm{Vi}}: n_{\mathrm{Si}-\mathrm{H}}$ $=1: 1.2$ and the weight ratio of ALN to BN fillers in the composites were fixed at $8: 2$. After stirring, the mixture was poured into stainless steel molds and degassed until all air bubbles vanished. Finally, the moulds were kept in the vacuum oven at $120{ }^{\circ} \mathrm{C}$ for 120 minutes to achieve curing. The total fraction of the ALN and BN fillers in the composites was varied from $0 \mathrm{wt} \%, 10 \mathrm{wt} \%, 20 \mathrm{wt} \%, 30 \mathrm{wt} \%, 40 \mathrm{wt} \%$ and $50 \mathrm{wt} \%$.

\subsection{Characterization}

The fracture surface morphology of the composites was observed by scanning electron microscopy (SEM, TESCAN MAIA3, Czech Republic) after being coated with gold.

The density of AlN/BN/ALSR composites was measured by Archimedes principle. The specific measurement method is as follows: the mass of the sample in the air $\left(m_{1}\right)$ and in the distilled water $\left(m_{2}\right)$ were respectively measured at room temperature by using an analytical balance (precision, $0.1 \mathrm{mg}$; BSA124S, Sartorius, Germany), and the sample density could be calculated by the relation

$$
\rho=\rho_{\mathrm{w}} m_{1} /\left(m_{1}-m_{2}\right)
$$

where $\rho_{\mathrm{w}}$ is the density of distilled water, which can be regarded as $1 \mathrm{~g} \mathrm{~cm}^{-3}$. The weight of samples was 2.5-3.5 $\mathrm{g}$. Three samples were made for each sample, and the density results were averaged.

Based on the laser flash method, the thermal conductivity $(\lambda)$ of the samples can be calculated:

$$
\lambda=\alpha \times C_{\mathrm{p}} \times \rho,
$$

where $\alpha$ is the thermal diffusivity, $C_{\mathrm{p}}$ is the specific heat capacity, and $\rho$ is the density of the sample. Thermal diffusivity and specific heat capacity was measured by flash thermal diffusivity instrument (LFA467, Netzsch Instruments Co.). The used samples were cylindrical with $12.7 \mathrm{~mm}$ diameter and $2 \mathrm{~mm}$ thickness. These tests were all performed at room temperature.

Thermo gravimetric analysis (TGA) was conducted on Synchronous thermal analyser (STA449F5, NETZSCH, German). The weight of samples were 5-10 $\mathrm{mg}$ and temperature range was from $30{ }^{\circ} \mathrm{C}$ to $800{ }^{\circ} \mathrm{C}$ with a heating rate of $10{ }^{\circ} \mathrm{C} \mathrm{min}^{-1}$.

The dielectric constant and dielectric loss of samples were measured using precision impedance analysers (WK6500B, Wayne Kerr, United Kingdom) and dielectric constant detector (S916, Shanghai Aiyi Electronic Equipment Co. Ltd., China) in the frequency range from $1 \mathrm{kHz}$ to $1 \mathrm{MHz}$ at the temperature of $25^{\circ} \mathrm{C}$.

The volume resistivity was measured using high resistance meter (ZC36, Shanghai Anbiao Electronics Co., Ltd., China) on DC voltage of $500 \mathrm{~V}$, power frequency $50 \mathrm{~Hz}$, temperature $25^{\circ} \mathrm{C}$. Thermal aging of the samples were carried out at $100{ }^{\circ} \mathrm{C}$ in an oven, and the aging times were $40 \mathrm{~d}, 70 \mathrm{~d}, 100 \mathrm{~d}$, and $150 \mathrm{~d}$.

\section{Results and discussion}

\subsection{Density}

Fig. 1 shows the density of at different filler contents. It can be seen that the density of the ALSR composites is improved with the increasing addition of AlN/BN fillers, which is mainly due to the higher density of the mixed filler than the pure silicone rubber. It is also apparent from Fig. 1 that the density of the ALSR composite is approximately linear with the content of the 


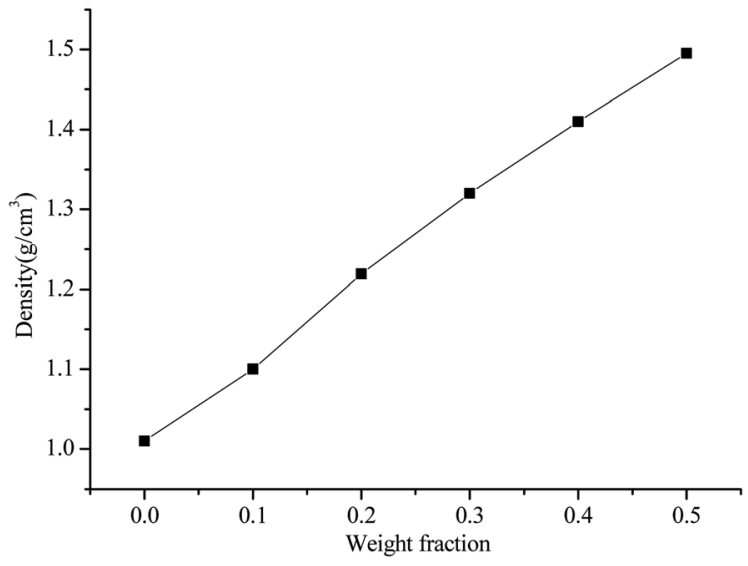

Fig. 1 Density of AIN/BN/ALSR composites with different filler loading.

mixed filler. Furthermore, due to the higher porosity in composites with higher filler content, the increase of density tends to decrease with the increase of filler proportion.

\subsection{Thermal conductivities of ALSR composites}

The thermal conductivity coefficient for the AlN/BN/ALSR composites at different filler contents are shown in Fig. 2.

It can be seen that thermal conductivity coefficient of AlN/ BN/ALSR composites is effectively improved after the addition of the filler, and increases as the ALN/BN loading increases. It can also be observed that the thermal conductivity coefficient of the ALSR composite increases slowly when the AlN/BN hybrid filler loading is less than $20 \mathrm{wt} \%$. The thermal conductivity of composites with $20 \mathrm{wt} \% \mathrm{AlN} / \mathrm{BN}$ loading is $0.237 \mathrm{~W}\left(\mathrm{~m}^{-1} \mathrm{~K}^{-1}\right)$, which is only 1.48 times higher than that of pure ALSR $(0.160 \mathrm{~W}$ $\left.\left(\mathrm{m}^{-1} \mathrm{~K}^{-1}\right)\right)$. The main reason for this phenomenon is that at low filler loading, AlN and BN particles are randomly dispersed within the ALSR matrix (Fig. 3(a)), and wrapped and separated by the ALSR matrix. The fillers are isolated from each other and do not form the heat conduction chain. The thermal conductivity of fillers does not contribute much to the thermal conductivity of ALSR composites. ${ }^{20,26}$ The thermal conductivity

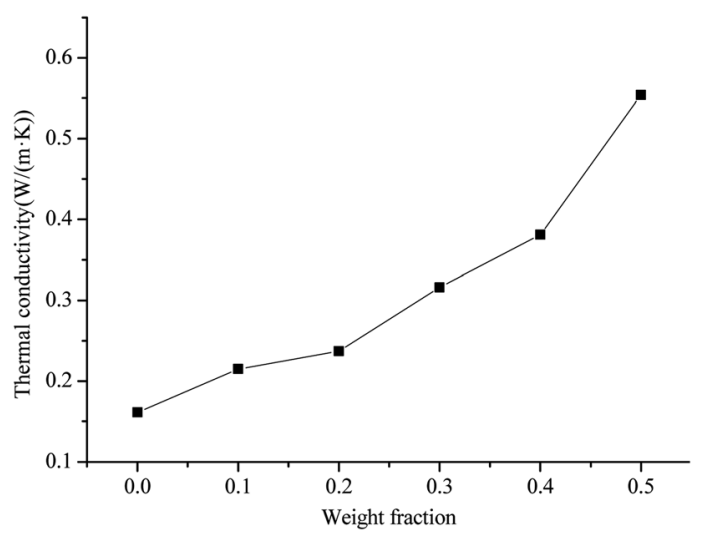

Fig. 2 Thermal conductivity of AIN/BN/ALSR composites with different filler loading.

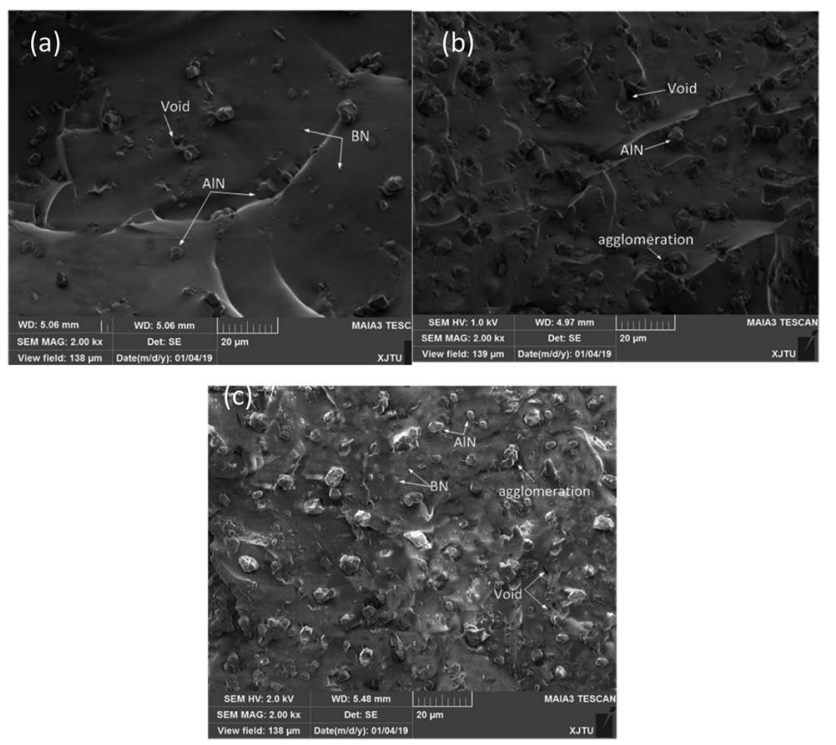

Fig. 3 SEM images of the fractured cross-section of the AIN/BN/ALSR composites with (a) $10 \mathrm{wt} \%$ AIN/BN filled and (b) $30 \mathrm{wt} \%$ AIN/BN filled (c) 50 wt\% AIN/BN filled.

of the composite is mainly determined by the polymer matrix itself. After the AlN/BN filler content is higher than $20 \%$ by weight, the thermal conductivity begins to increase rapidly. The thermal conductivity of composites with $50 \mathrm{wt} \%$ AlN/BN loading is $0.554 \mathrm{~W}\left(\mathrm{~m}^{-1} \mathrm{~K}^{-1}\right)$, which is 2.34 times higher than that of $20 \mathrm{wt} \%$ ALSR composites. This is because as the filler content increases, the possibility of touching and connection between the AlN/BN particles increases (Fig. 3(b) and (c)), and effective thermally conductive channels \& networks of AlN/BN begins to form, resulting in a much reduced thermal contact resistance and rapid improvement of the thermal conductivity of AlN/BN/ALSR composites.

\subsection{Thermal stability of ALSR composites}

Thermal stability of the ALSR composites was investigated by thermal gravimetric analysis. The TGA and DTG curves of pure ALSR and ALSR composites under air atmosphere are shown in Fig. 4, and the characteristic data of those curves is shown in Table 1. As demonstrated, the thermal degradation of pure ALSR can be clearly divided into two stages. The first stage of thermal decomposition starts at about $312{ }^{\circ} \mathrm{C}$, and the temperature for peak degradation is about $360^{\circ} \mathrm{C}$. The weight loss at this stage is mainly due to the oxidation of the methyl group in the ALSR chain, which initiates the melting and depolymerisation of the ALSR chain. ${ }^{27}$ The second stage starts at $405{ }^{\circ} \mathrm{C}$ and the temperature for peak degradation is about $495{ }^{\circ} \mathrm{C}$. The weight loss at this stage is mainly attributed to the methyl groups broke away from the chains and the increased depolymerisation of the ALSR chain. ${ }^{28,29}$ When the temperature reached $800{ }^{\circ} \mathrm{C}$, the residue amount of pure ALSR was $36.88 \%$. For BN/AlN/ALSR composite, the thermal weight loss process can also be divided into two stages, and as the filler content increases, the limit between the two-stage thermal weight losses gradually decreases. Furthermore, the characteristic temperature of 

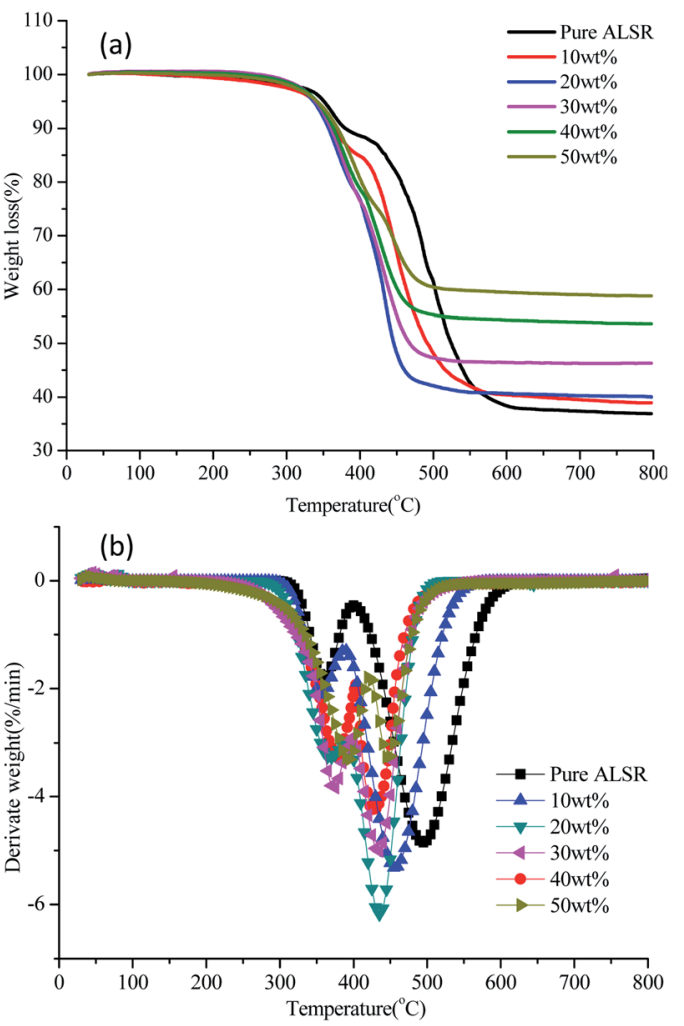

Fig. 4 TGA (a) and DTG (b) curves of AIN/BN/ALSR composites with different filler content under air atmosphere.

5\% weight loss (T5) of ALSR composites is slightly lower than that of pure ALSR, the mass loss of the first stage thermal decomposition increases, and the peak decomposition temperature of the second stage thermal decomposition decreases. There are three reasons for this phenomenon: (1) the addition of fillers affects the addition reaction of Vi-PDMS and PHMS, which reduces the polymerization degree and increases the vulcanized low molecular weight polymers; ${ }^{25}(2)$ the volatilization temperature of the solvent and adsorbed water brought by the filler is low; (3) the defects including voids and cracks caused by fillers and matrix may also have a negative impact on the thermal degradation process. ${ }^{10}$ At the same time, because the decomposition temperature and specific heat capacity of AlN and BN particles are higher than that of ALSR, the peak decomposition temperature of first stage of thermal decomposition of BN/AIN/ALSR composite is higher than that of pure ALSR, and the residual weight at $800{ }^{\circ} \mathrm{C}$ increases largely. In summary, the addition of fillers has both positive and negative effects. Compared to pure ALSR, the temperature at $5 \%$ weight loss is slightly lower, but the high temperature residue weight is significantly increased. And the T5 showed an upward trend with the increase of fillers. Therefore, the thermal stability of the BN/ AlN/ALSR composite is improved at high temperatures as a whole.

\subsection{Dielectric properties of ALSR composites}

The dependence of relative dielectric constant and dielectric loss on frequency of BN/AlN/ALSR composites at different filler content is shown in Fig. 5 . The frequency range is from $1 \mathrm{kHz}$ to 1000 kHz. From Fig. 5, it can be seen that the relative permittivity and dielectric loss of BN/AlN/ALSR composites increases with filler loading. This is because that for BN/AlN/ALSR composite, besides the dipole polarization of the rubber chain segments, the interfacial polarization caused by the addition of high dielectric constant fillers into the rubber matrix also enhances the relative
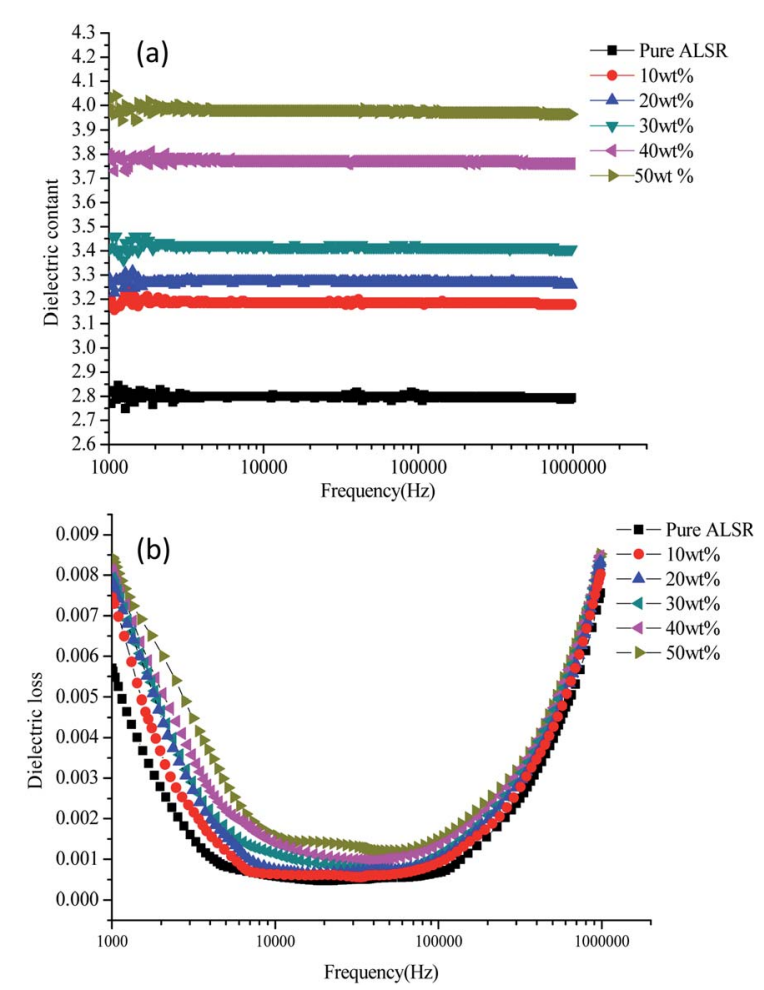

Fig. 5 Dielectric constant (a) and dielectric loss (b) curves of AIN/BN/ ALSR composites.

Table 1 Characteristic data of TGA and DTG curves under air atmosphere

\begin{tabular}{|c|c|c|c|c|}
\hline Pure ALSR & 350.74 & 360 & 495 & 36.88 \\
\hline $20 \mathrm{wt} \%$ & 336.73 & 366 & 435 & 40.00 \\
\hline $30 \mathrm{wt} \%$ & 339.66 & 374 & 435 & 46.30 \\
\hline $40 \mathrm{wt} \%$ & 341.20 & 378 & 427 & 53.64 \\
\hline
\end{tabular}


permittivity and dielectric loss of the ALSR composites. ${ }^{30-32}$ Moreover, from Fig. 5(a), it is obviously that the relative permittivity of the composite samples does not show appreciable differences within the measured frequency range, since there is hardly any change in the polarization mechanism. It can also be observed in Fig. 5(b), the dielectric loss of samples decreases firstly and then increases with increasing frequency. The dielectric loss of ALSR composite mainly includes the conductance loss and relaxation polarization loss. When the measured frequency is low, the dipole polarization and the interface polarization can keep up with the change of the electric field, so the loss of relaxation polarization is small. ${ }^{33,34}$ The conductance loss caused by leakage current is the main loss. As the frequency increases, the conductance loss decreases inversely, but the relaxation polarization loss increases gradually because the dipole polarization and the interfacial polarization fail to catch up with the change cycle of the electric field. Therefore, dielectric loss increases gradually after a stable period of time. In summary, although the dielectric constant and dielectric loss of the composite sample increase with the increase of filler loading, the value is still low. Taking $50 \mathrm{wt} \%$ composite samples as an example, its dielectric constant is 4.0 and dielectric loss is 0.0085 at $1 \mathrm{MHz}$. Therefore, the ALSR composite can be used as encapsulation material for power electronic components.

\subsection{Volume resistivity of ALSR composites}

The volume resistivity of the polymer material mainly depends on the concentration, mobility and charge amount of carrier. The concentration of the movable carrier in the polymer composite is determined by the matrix itself, and the addition of the ceramic particles will not increase the movable load. The volume resistivity of the BN/AlN/ALSR composite before thermal aging as a function of the filler loading is shown in Fig. 6(a). It can be seen from Fig. 6(a) that the volume resistivity of the samples filled with BN/AlN filler is higher than that of pure ALSR, and increases first and then decreases as the BN/AlN filler loading increases. The volume resistivity of the ASLR composite increases as the filler loading is low, which can be attributed to a decrease in carrier mobility. There are two main reasons for the decrease of carrier mobility. ${ }^{35-37}$ One is that the BN/AlN filler adsorbs some carriers in ALSR, which reduces the number of carriers in the sample. Another is that the addition of fillers introduces a large number of traps between the interface of the filler and the rubber matrix. Then the movable carriers are trapped by the traps on the interface, which makes the carrier mobility decrease. As the filler loading increases, the interface regions between adjacent particles may overlap. Then a local conductive channel is formed and the movable carriers are transported along the conductive channel. After obtaining sufficient energy under the applied electric field, the barrier is jumped over to participation in conduction, resulting in a decrease in resistivity. ${ }^{38}$ With the increase of filling fraction, the change of carrier mobility becomes smaller and smaller, and the volume resistivity tends to be stable.

The volume resistivity of the BN/AlN/ALSR composite after thermal aging as a function of the aging time is shown in Fig. 6(b).

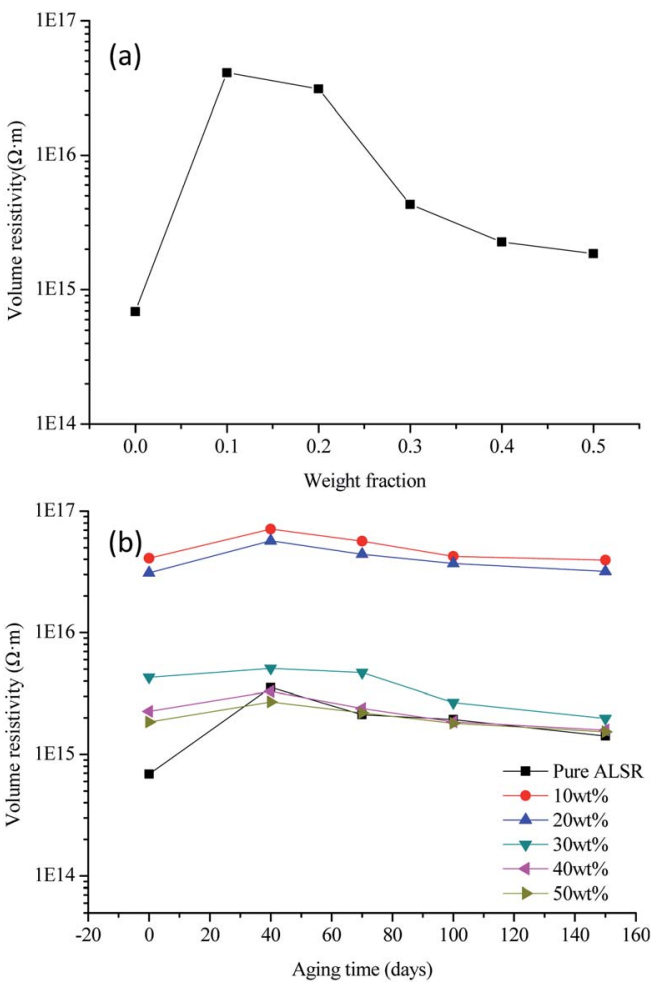

Fig. 6 Volume resistivity before thermal aging (a) and after thermal aging (b) curves of AIN/BN/ALSR composites.

It can be seen from Fig. 6(b) that the volume resistivity of all samples increases first and then decreases with the increase of aging time. This is attributed to the fact that in the early stage of the thermal aging, the low molecular weight gradually precipitates under the action of heat, and the internal re-crosslinking reaction of the material predominates, resulting in a decrease in the number and mobility of carriers which would make an increase in volume resistivity. ${ }^{39}$ With the prolongation of thermal aging time, the degree of thermal degradation inside the composite material is gradually increased, leading to the breakage of the main chain, side chain, cross-linking bonds of ALSR, and the generation of a large number of free radicals and polar groups. This greatly increases the number and mobility of carriers, and significantly reduces the volume resistivity. It can also be seen from Fig. 6(b) that compared with the ALSR composites, the volume resistivity of pure ALSR varies most with thermal aging time. The ALSR composite sample, regardless of the filling amount of the inorganic filler, the volume resistivity does not change much with the thermal aging time. This may be because the thermal stability of the ALSR composites increases after the addition of the fillers, which inhibits the recrosslinking reaction and the degradation reaction to a certain extent, so that the volume resistivity of the composite material does not change much with the thermal aging time.

\section{Conclusions}

In this research, AlN and BN co-filled ALSR with the purpose of being applied in insulation packaging of high voltage power 
electronic devices was studied, and the effects of the filling fraction of AlN and $\mathrm{BN}$ with a fixed weight ratio of $8: 2$ on various properties of the composites were discussed. The main conclusions are as follows.

The thermal conductivity of AlN/BN/ALSR composites increase with the filler content increase, the maximum value can reach 3.4 times of pure ASLR. The TGA results reveal that although the temperature of $5 \%$ weight loss is slightly lower than that of pure ALSR, the residual amount is greatly increased at $800{ }^{\circ} \mathrm{C}$. Therefore, the overall thermal stability has increased slightly.

The volume resistivity of AlN/BN/ALSR composites before thermal aging increases first and then decreases with the increase of filler content, and is higher than that of pure ALSR. The volume resistivity of AlN/BN/ALSR composites after thermal aging increases first and then decreases with the increase of aging time, and pure ALSR varies the most than that of ALSR composites.

The dielectric constant and dielectric loss of AlN/BN/ALSR composites increases with the increase of filler loading. The dielectric constant of 3.98 and dielectric loss of 0.0085 is obtained for $50 \mathrm{wt} \%$ of AlN/BN/ALSR composites at $1 \mathrm{MHz}$, which satisfies the applications in the field of insulation packaging.

\section{Conflicts of interest}

There are no conflicts to declare.

\section{Acknowledgements}

This work was supported by the National Science and Technology Major Project of the Ministry of Science and Technology of China (No. 2017YFF0104403).

\section{References}

1 R. Heiderhoff, A. Makris and T. Riedl, Mater. Sci. Semicond. Process., 2016, 43, 163-176.

2 H. Chen, V. V. Ginzburg, Y. Jian, Y. Yang, L. Wei, H. Yan, L. Du and B. Chen, Prog. Polym. Sci., 2016, 59, 41-85.

3 Z. Pan, S. Rui, S. Zhu, Y. Kang, B. Huang and L. Zhu, J. Adhes. Sci. Technol., 2018, 32, 1-14.

4 A. Bar-Cohen, A. Kraus and S. Davidson, Mech. Eng., 1983, 105, 53-59.

5 C.-C. Kuo and J.-X. Lin, Int. J. Adv. Manuf. Technol., 2019, 101, 615-625.

6 E. Delebecq and F. Ganachaud, ACS Appl. Mater. Interfaces, 2012, 4, 3340-3352.

7 C. Huang, Q. Xin and R. Yang, Mater. Sci. Eng., R, 2018, 132, 1-22.

8 C. Yu, J. Zhang, T. Wei and D. F. Xiao, $R S C A d v .$, 2018, 8, 21948-21967.

9 Y. Ying, Z. Chi, B. Tang, E. Li and S. Zhang, J. Mater. Sci.: Mater. Electron., 2018, 29, 14890-14896.

10 J. Gu, X. Meng, Y. Tang, L. Yang, Z. Qiang and K. Jie, Composites, Part A, 2017, 92, 27-32.

11 T. Huang, X. Zeng, Y. Yao, R. Sun, F. L. Meng, J. B. Xue and C. P. Wong, RSC Adv., 2017, 7, 23355-23362.
12 S. Na, H. Pan, X. Hou, S. Cui, L. Shi and D. Peng, RSC Adv., 2017, 7, 46306-46312.

13 Z. Wang, Y. Cheng, H. Wang, M. Yang, Y. Shao, X. Chen and T. Tanaka, J. Mater. Sci., 2017, 52, 4299-4308.

14 G. Duan, Y. Wang, J. Yu, J. Zhu and Z. Hu, Front. Mater. Sci., 2019, 13, 64-76.

15 Y. Guo and S. N. Leung, Mater. Chem. Phys., 2018, 214, 221228.

16 R. Seokgyu, O. Taeseob and K. Jooheon, $R S C$ Adv., 2018, 8, 22846-22852.

17 D. Kuscer, I. Bantan, M. Hrovat and B. Malič, J. Eur. Ceram. Soc., 2017, 37, 739-746.

18 P. Liu, L. Li, L. Wang, T. Huang, Y. Yao and W. Xu, J. Alloys Compd., 2019, 774, 396-404.

19 L. K. Namitha, S. Ananthakumar and M. T. Sebastian, J. Mater. Sci.: Mater. Electron., 2015, 26, 891-897.

20 Y. K. Kim, J. Y. Chung, J. G. Lee, Y. K. Baek and P. W. Shin, Composites, Part A, 2017, 98, 184-191.

21 J. Zha, Z. Dang, W. Li, Y. Zhu and G. Chen, IEEE Trans. Dielectr. Electr. Insul., 2014, 21, 1989-1996.

22 J. Qiu, X. Lai, W. Fang, H. Li and X. Zeng, Polym. Degrad. Stab., 2017, 144, 176-186.

23 Y. Li, X. Zeng, X. Lai, H. Li and W. Fang, Polym. Test., 2017, 63, 92-100.

24 A. R. Verma and B. S. Reddy, IEEE Trans. Dielectr. Electr. Insul., 2018, 25, 46-52.

25 W. Fang, X. Zeng, X. Lai, H. Li, C. Xie, W. Chen and Y. Zhang, IEEE Trans. Dielectr. Electr. Insul., 2017, 23, 3668-3675.

$26 \mathrm{~S} . \mathrm{He}, \mathrm{J} . \mathrm{Hu}, \mathrm{C}$. Zhang, J. Wang, L. Chen, X. Bian, J. Lin and X. Du, Polym. Test., 2018, 67, 295-301.

27 E. Delebecq, S. Hamdani, J. Raeke, J. M. Lopez and F. Ganachaud, ACS Appl. Mater. Interfaces, 2011, 3, 869-880.

28 C. Xie, X. Zeng, W. Fang, X. Lai and H. Li, Polym. Degrad. Stab., 2017, 142, 263-272.

29 G. Camino, S. M. Lomakin and M. Lazzari, Polymer, 2001, 42, 2395-2402.

30 M. T. Nazir, T. Phung, M. Hoffman and S. Yu, Mater. Lett., 2017, 209, 421-424.

31 L. K. Namitha, S. Ananthakumar and M. T. Sebastian, J. Mater. Sci.: Mater. Electron., 2014, 26, 891-897.

32 F. Rogti, A. Mekhaldi and C. Laurent, IEEE Trans. Dielectr. Electr. Insul., 2008, 15, 1478-1485.

33 N. Shang, Q. Chen and X. Wei, Materials, 2018, 11, 403-414. 34 M. Donnay, S. Tzavalas and E. Logakis, Compos. Sci. Technol., 2015, 110, 152-158.

35 P. G. Ren, S. Y. Hou, F. Ren, Z. P. Zhang, Z. F. Sun and L. Xu, Composites, Part A, 2016, 90, 13-21.

36 P. G. Ren, X. H. Si, Z. F. Sun, F. Ren, L. Pei and S. Y. Hou, J. Polym. Res., 2016, 23, 21.

37 J. Zhao, F. Du, W. Cui, P. Zhu, X. Zhou and X. Xie, Composites, Part A, 2014, 58, 1-6.

38 P. Chu, H. Zhang, J. Zhao, F. Gao, Y. Guo, B. Dang and Z. Zhang, Composites, Part A, 2017, 99, 139-148.

39 Y. Wang, C. Wang, Z. Zhang and K. Xiao, Nanomaterials, 2017, 7, 320-333. 